\title{
Should governments continue lockdown to slow the spread of covid-19?
}

Until we have a meaningful alternative, lockdown is the only thing we can do to prevent further catastrophic spread of the virus, says Edward R Melnick. But John PA loannidis argues that any benefits of lockdown depend on its effectiveness and the covid-19 burden-and that the harms are multifarious

\section{Edward R Melnick assistant professor ${ }^{1}$, John P A loannidis professor ${ }^{2}$}

'Department of Emergency Medicine, Yale School of Medicine, New Haven, CT, USA; ${ }^{2}$ Departments of Medicine, of Epidemiology and Population Health, of Biomedical Data Sciences, and of Statistics; and Meta-Research Innovation Center at Stanford (METRICS), Stanford University, Stanford, CA, USA

\section{Yes-Edward R Melnick}

There is still much we do not understand about covid-19. Since the first case was confirmed in the US just over three months ago we have seen cases overwhelm healthcare infrastructure in endemic areas, ${ }^{1}$ while also learning that asymptomatic and presymptomatic transmission may be rapid and widespread. ${ }^{2}$ Though reassuring, the preliminary assessments of covid-19 prevalence and under-ascertainment rates must be interpreted cautiously, considering sample selection bias and high variability in local rates of infection, transmission, and testing. ${ }^{3}$ Indeed, preliminary fatality rate estimates are likely overestimated, though still likely to be more than 10 times greater than from seasonal flu. ${ }^{4}$

Regardless, high transmission in a population naive to covid-19 has contributed to more than 250000 deaths globally and has substantially taxed healthcare resources and capacity. Even the most conservative predictions show that covid-19 deaths may exceed those from any other infectious diseases in our lifetimes. ${ }^{5}$ And, at the time of writing, most of the world's population likely remains susceptible to covid-19.

In the absence of a safe and effective vaccine, treatment, or prophylaxis, non-pharmaceutical interventions are the only options available to slow the virus's spread. These include physical distancing, hygiene, masks, isolation of infected people and their contacts, and lockdowns, such as closures of school and businesses and bans on public gatherings and travel. The best strategy to reduce transmission of such an infectious disease involves aggressive, early detection, with isolation of infected individuals to minimise transmission before the disease can become endemic locally. ${ }^{6}$
This strategy proved particularly difficult with covid-19, most likely because of the delay between infection and manifestation of severe symptoms and the lack of testing available. As a result, strategies have pivoted from containment to mitigation, ushering in lockdowns on a scale unprecedented in the modern collective consciousness.

\section{A blunt but necessary tool}

Lockdowns are, comparatively, the most draconian non-pharmaceutical intervention. When implemented successfully, they decrease disease transmission by limiting human contact at scale. Historical archival analysis of 43 cities in the 1918-19 flu pandemic shows a strong association between lockdowns and delayed or reduced peak mortality rates, as well as reduced cumulative deaths. ${ }^{7}$ Earlier implementation and longer lockdowns were also associated with reduced total mortality.

Lockdowns are not without cost, risk, or harm. The resulting economic, social, and emotional toll of covid-19 lockdowns have been catastrophic and vast. ${ }^{8}$ And medical consequences of lockdowns are beginning to emerge, with a paradoxical increase in preventable deaths due to avoidance in seeking necessary medical care, resulting in excess morbidity and mortality from non-covid conditions. ${ }^{9}$

But restrictions cannot safely be lifted without the capacity for massive testing, contact tracing, and adequate protection for high risk populations. Otherwise, covid-19's spread could accelerate in communities that have not yet experienced their peak case incidence rate, and second waves could be deadlier in communities that have reopened after successful lockdowns. ${ }^{7}$ Of course, it is not known whether a second wave will occur-or 
how severe it might be. If one does occur, preparation is essential. Hopefully, less blunt non-pharmaceutical interventions (such as masks, testing and tracing, and social distancing) will be adequate to contain a second wave.

But hope is not a strategy. Aggressive, free community screening without physician referral, along with targeted testing in high risk locations (nursing homes, prisons, homeless shelters) and of random populations, could obviate the need for lockdowns. ${ }^{10}$ Yet, in the US, we have not prioritised the development of necessary capacity for massive testing; nor is there the public will to employ such a strategy. Until then, or until an alternative strategy emerges, lockdowns will continue to be essential in mitigating this growing pandemic.

\section{No-John PA loannidis}

Lockdown was justified initially, when announcements declared a new, contagious virus with a $3.4 \%$ fatality rate and no asymptomatic infections. The prospect of 50 million deaths matched that of the 1918 flu pandemic. However, we know that undetected infections are the vast majority. The people infected outnumber those confirmed by polymerase chain reaction tests, anything from fivefold (Gangelt, Germany) to more than 500-fold (Kobe, Japan).

The infection fatality rate is thus vastly lower than the documented case fatality rates. Moreover, most covid-19 deaths affect people with limited life expectancy, ${ }^{11}$ while the average age at death in the 1918 flu pandemic was 28 . The expected loss of quality adjusted life years, even without aggressive lockdown measures, is 100 to 1000 times lower than in 1918 - perhaps comparable with (if not lower than) typical seasonal flu, which kills 34800 (95\% confidence interval 13 200 to 97200 ) children every year with acute lower respiratory infections, ${ }^{12}$ in contrast with covid-19, which overwhelmingly spares children.

Even if covid-19 is far milder than feared, it can still devastate in specific settings. Massacres in overwhelmed hospitals with contaminated personnel ${ }^{13}$ and in nursing homes ${ }^{14}$ represent the lion's share of deaths. Hospital preparedness, universal personnel screening, draconian infection control, and social distancing in these locations are indispensable.

However, blind lockdown of entire populations has questionable added benefits. Locking down healthy, no-risk people and transferring covid-19 patients to nursing homes was absurd. Proponents of "lockdown to flatten the curve" should acknowledge that this gains time for hospital preparedness but that most, if not all, covid-19 deaths will still happen when measures are relaxed-unless effective treatments and/or vaccines emerge. Moreover, the lockdown-to-flatten-the-curve rationale ignores seasonality and espouses 100 year old observational data from a 1918 pandemic with an infection fatality rate 100 times higher than covid-19.

\section{Prolonged harms}

Lockdowns have multiple components. Some, such as avoiding mass gatherings, may work; others may not. Some may even increase the number of covid-19 deaths-for instance, school closures may increase frail relatives' exposure to children. But, regardless of the combination, lockdowns bring multifarious harms beyond those related to the SARS-CoV-2 virus, such as the consequences of health system dysfunction and extended harms eroding health, the economy, and society at large.

Lockdowns implemented during high infectious activity will force infective people to spend more time with frail relatives in cramped spaces. Low wage, essential workers adopt higher risks, and shelters for vulnerable homeless people become infection hotspots, while wealthy, healthy citizens get to stay at home. Stress may also affect our immune responses to respiratory infections. And, with the added horror spread by various media sources, lockdowns represent uniquely stressful experiences.

Under lockdown conditions many patients with acute, treatable conditions (such as coronary syndromes) avoid seeking care. ${ }^{1516}$ This disruption may be seen in the excess deaths accruing so far in the covid-19 lockdown. ${ }^{17}$ Patients with cancer whose treatment is delayed have worse outcomes. ${ }^{18}$ And when patients avoid hospitals many health systems suffer financially, furlough personnel, and cut services. Covid-19 overwhelmed a few dozen hospitals, but covid-19 countermeasures have already jeopardized thousands of them.

Prolonged lockdowns fuel economic depression, creating mass unemployment. Jobless people may lose health insurance. Entire populations may witness decreased quality of life and mental health. ${ }^{19}$ Gun sales in the US have increased sharply since the lockdown began, with unpredictable consequences.

Underprivileged populations and those in need are hit harder by crises. People at risk of starvation worldwide have already exceeded one billion. ${ }^{20} \mathrm{We}$ are risking increased suicides, domestic violence, and child abuse. Malaise and societal disintegration may also advance, with chaotic consequences such as riots and wars.

And how long a lockdown is enough? If we open now, will lockdown recur in autumn? Next year? Whenever authoritarianism so wishes? No dictatorship could imagine a better precedent for absolute control.

Lockdowns were desperate, defendable choices when we knew little about covid-19. But, now that we know more, we should avoid exaggeration. ${ }^{21} \mathrm{We}$ should carefully and gradually remove lockdown measures, with data driven feedback on bed capacity and prevalence/incidence indicators. Otherwise, prolonged lockdowns may become mass suicide.

ERM thanks Joshua Niforatos, Keith Sigel, and Howard Forman for reading and critiquing a draft of his portion of the manuscript and Bidisha Nath and Raj Mehta for contributing input on relevant medical literature.

Competing interests: We have read and understood BMJ policy on declaration of interests and declare the following interests. JPAI declares no competing interests. ERM is supported in part by grant number UH3DA047003 from the National Institute on Drug Abuse and two Practice Transformation Initiatives from the American Medical Association. The content is solely the responsibility of the authors and does not necessarily represent the official views of any funding agency.

Provenance and peer review: Commissioned; not externally peer reviewed.

Emanuel EJ, Persad G, Upshur R, etal . Fair allocation of scarce medical resources in the time of covid-19. N Engl J Med 2020;382:2049-55. 10.1056/NEJMsb2005114. 32202722

2 Arons MM, Hatfield KM, Reddy SC, etal . Presymptomatic SARS-CoV-2 infections and transmission in a skilled nursing facility. N Engl J Med 2020. 10.1056/NEJMoa2008457. 32329971

3 Bendavid E, Mulaney B, Sood N, et al. Covid-19 antibody seroprevalence in Santa Clara County, California. 10.1101/2020.04.14.20062463.

4 Niforatos JD, Melnick ER, Faust JS. Covid-19 fatality is likely overestimated. BMJ 2020;368:m1113. 10.1136/bmj.m1113 32198267

5 Basu A. Estimating the infection fatality rate among symptomatic COVID-19 cases in the United States. Health Aff (Millwood) 2020:f202000455. 10.1377/hlthaff.2020.00455. 32379502

6 Hellewell J, Abbott S, Gimma A, etal. Centre for the Mathematical Modelling of Infectious Diseases COVID-19 Working Group. Feasibility of controlling COVID-19 outbreaks by isolation of cases and contacts. Lancet Glob Health 2020;8:e488-96. 10.1016/S2214-109X(20)30074-7 32119825

7 Markel H, Lipman HB, Navarro JA, etal . Nonpharmaceutical interventions implemented by US cities during the 1918-1919 influenza pandemic. JAMA 2007;298:644-54. 10.1001/jama.298.6.644 17684187 
8 Nicola M, Alsafi Z, Sohrabi C, etal . The socio-economic implications of the coronavirus pandemic (COVID-19): A review. Int J Surg 2020;78:185-93.

10.1016/j.jijsu.2020.04.018. 32305533

9 Brown E, Tran AB, Reinhard B, et al. US deaths soared in early weeks of pandemic, far exceeding number attributed to covid-19. Washington Post $2020 \mathrm{Apr} 27$. https://www. washingtonpost.com/investigations/2020/04/27/covid-19-death-toll-undercounted/.

10 Kaplan EH, Forman HP. Logistics of aggressive community screening for coronavirus 2019. JAMA Health Forum 2020;1:e200565-e200565. https://jamanetwork.com/channels/ health-forum/fullarticle/2765693.

11 loannidis JPA, Axfors C, Contopoulos-loannidis DG. Population-level covid-19 mortality risk for non-elderly individuals overall and for non-elderly individuals without underlying diseases in pandemic epicenters. medRxiv 2020 (preprint). 10.1101/2020.04.05.20054361.

12 Wang X, Li Y, O'Brien KL, etal. Respiratory Virus Global Epidemiology Network. Global burden of respiratory infections associated with seasonal influenza in children under 5 years in 2018: a systematic review and modelling study. Lancet Glob Health 2020;8:e497-510. 10.1016/S2214-109X(19)30545-5 32087815

13 Boccia S, Ricciardi W, loannidis JPA. What other countries can learn from Italy during the covid-19 pandemic. JAMA Intern Med 2020. 10.1001/jamainternmed.2020.1447. 32259190

14 Booth $\mathrm{R}$. Half of coronavirus deaths happen in care homes, data from EU suggests. Guardian 2020. https://www.theguardian.com/world/2020/apr/13/half-of-coronavirusdeaths-happen-in-care-homes-data-from-eu-suggests.

15 De Filippo O, D'Ascenzo F, Angelini F, etal . Reduced rate of hospital admissions for ACS during covid-19 outbreak in northern Italy. N Engl J Med 2020 10.1056/NEJMc2009166. 32343497
16 Metzler B, Siostrzonek P, Binder RK, Bauer A, Reinstadler SJ. Decline of acute coronary syndrome admissions in Austria since the outbreak of COVID-19: the pandemic response causes cardiac collateral damage. Eur Heart J 2020;41:1852-3.

10.1093/eurhearti/ehaa314. 32297932

17 Docherty K, Butt J, de Boer R, et al. Deaths from covid-19: Who are the forgotten victims? medRxiv 2020 (preprint). https://www.medrxiv.org/content/10.1101/2020.04.21. 20073114v2.abstract.

18 Sud A, Jones ME, Broggio J, et al. Collateral damage: the impact on cancer outcomes of the covid-19 pandemic. medRxiv 2020 (preprint). https://www.medrxiv.org/content/10. 1101/2020.04.21.20073833v2.full.

19 Moser DA, Glaus J, Frangou S, et al. Years of life lost due to the psychosocial consequences of covid-19 mitigation strategies based on Swiss data. medRxiv 2020 (preprint). https://www.medrxiv.org/content/10.1101/2020.04.17.20069716v2.abstract.

20 Picheta R. Coronavirus pandemic will cause global famines of "biblical proportions," UN warns. CNN2020. https://www.cnn.com/2020/04/22/africa/coronavirus-famine-un-warningintl/index.html.

21 Ioannidis JPA. Coronavirus disease 2019: The harms of exaggerated information and non-evidence-based measures. Eur J Clin Invest 2020;50:e13222.

10.1111/eci.13222 32191341

This article is made freely available for use in accordance with BMJ's website terms and conditions for the duration of the covid-19 pandemic or until otherwise determined by BMJ. You may use, download and print the article for any lawful, non-commercial purpose (including text and data mining) provided that all copyright notices and trade marks are retained.

https://bmj.com/coronavirus/usage 